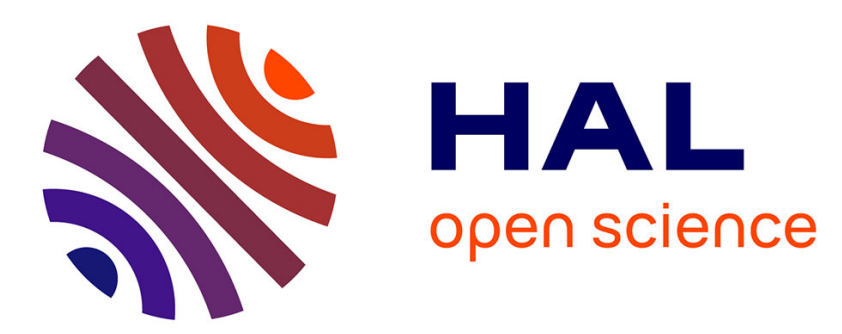

\title{
Searching out the hydrogen absorption/desorption limiting reaction factors: strategies allowing to increase kinetics
}

Ali Zeaiter, David Chapelle, Philippe Nardin

\section{- To cite this version:}

Ali Zeaiter, David Chapelle, Philippe Nardin. Searching out the hydrogen absorption/desorption limiting reaction factors: strategies allowing to increase kinetics. International Symposium on MetalHydrogen Systems, Jul 2014, Manchester, United Kingdom. 10.1016/j.jallcom.2015.01.006 . hal02300536

\section{HAL Id: hal-02300536 \\ https://hal.science/hal-02300536}

Submitted on 29 Sep 2019

HAL is a multi-disciplinary open access archive for the deposit and dissemination of scientific research documents, whether they are published or not. The documents may come from teaching and research institutions in France or abroad, or from public or private research centers.
L'archive ouverte pluridisciplinaire HAL, est destinée au dépôt et à la diffusion de documents scientifiques de niveau recherche, publiés ou non, émanant des établissements d'enseignement et de recherche français ou étrangers, des laboratoires publics ou privés. 


\title{
Searching out the hydrogen absorption/desorption limiting reaction factors: strategies allowing to increase kinetics
}

\author{
Ali Zeaiter*, David Chapelle and Philippe Nardin \\ FEMTO-ST, Department of Applied Mechanics, 24 rue de l'épitaphe, \\ 25000 Besançon, France \\ E-mail of the corresponding author: ali.zeaiter@femto-st.fr
}

\begin{abstract}
:
Hydrogen gas has become one of the most promising energy carriers. Main breakthrough concerns hydrogen solid storage, specially based on intermetallic material use. Regarding the raw material abundance and cost, the $\mathrm{AB}$ type alloy FeTi is an auspicious candidate to store hydrogen. Its absorption/desorption kinetics is a basic hindrance to common use, compared with more usual hydrides.

First, discussions based on literature help us identifying the successive steps leading to metal hydriding, and allow to introduce the physical parameters which drive or limit the reaction. This analysis leads us to suggest strategies in order to increase absorption/desorption kinetics. Attention is then paid to a thermodynamics model, allowing to describe a macroscopic solid storage reactor. Thus, we can achieve a simulation which describes the overall reaction inside the hydrogen reactor and, by varying the sub-mentioned parameters (thermal conductivity, the powder granularity, environment heat exchange...), we attempt to hierarchy the reaction limiting factors. These simulations are correlated to absorption/desorption experiments for which pressure, temperature and hydrogen flow are recorded.
\end{abstract}

Keywords: Hydrogen, absorption, desorption, hydride materials, thermodynamic model, kinetics

\section{1-Introduction}

Solid storage coupled with intermetallic is one of the most promising technologies that can provide an efficient and secure holding of the hydrogen gas comparing with the traditional ways such as gas and liquid storage. The solid storage method can be accomplished with a variety of structural type of intermetallic like $\left(\mathrm{AB}, \mathrm{AB}_{2}, \mathrm{AB}_{5}, \mathrm{AB}_{3}\right.$ and $\left.\mathrm{A}_{2} \mathrm{~B}_{7}\right)$. By inspecting deeply the different structural types, the FeTi $\mathrm{AB}$ intermetallic has received a special attention because of the plenty in raw material and the reversible characteristic of the hydride reaction, in other word: absorption and desorption processes. However, in order to ensure that the hydride reaction meets engineering requirements, this alloy still need to be characterized to overcome all challenges such as a harsh activation behavior or a slow reaction kinetics. A pure FeTi needs an applied pressure in the range of 30 bar and a temperature in the range of $670 \mathrm{~K}$ to be activated, and it was reported that kinetics are very slow (an absorption stage of a fully activated sample can take over than 10 hours to reach the maximum of storage capacity $\sim 1.8$ wt.\%). Focusing on the hydride reaction of FeTi alloy, this reaction is described according to the following chemical equation: $\mathrm{nFeTi}+\mathrm{H}_{2} \leftrightarrow \mathrm{nFeTiH}_{2 / \mathrm{n}} \bar{\mp} \Delta H$, where $\Delta H$ is the heat generated or needed during absorption and desorption respectively, because as well 
known, while the absorption stage the chemical reaction is exothermic, contrariwise the reaction is endothermic for the desorption stage.

All physics phenomena should be described mathematically by using concrete equations which allow to find the system response based on initial conditions, i.e. input variables and material properties for the hydrogen absorption/desorption process. A thermodynamic model is developed based on several physics principles: it describes the reaction from a macro-scale point of view. One of the most relevant issues on the reaction rate is the thermal management and specially the overall heat transfer coefficient. It has been reported that the thermal conductivity of the powders decrease in correlation with the number of repeating cycle to reach a very low value in the range of $0.1 \mathrm{~W} / \mathrm{mK}$. The thermal conductivity can be mended by several ways such as powders compacting or/and the intercalation of some materials that have an important thermal conductivity. Those metals can be copper wire, porous graphite, aluminum foam, etc. $\mathrm{K}$ wang et al. [1] used the porous graphite with powders compacting to enhance thermal conductivity and have reported that $\lambda$ is increased to reach $3 \mathrm{~W} / \mathrm{mK}$. Also several works have been reported on material doping, as an example P. Mandal et al. [2] have worked on the FeTi (Mn) which have $46 \% \mathrm{Fe}, 50 \% \mathrm{Ti}$, and $4 \% \mathrm{Mn}$, the alloy is mixed with $\mathrm{Mg}$ according to the following composition $40 \%$ (FeTi Mn) and 60\% Mg. They have shown that $80 \%$ of the total amount of hydrogen is desorbed within $10 \mathrm{~min}$. In the other hand, fabrication methods can be listed as one of the pre-treatment ways to increase kinetics. $\mathrm{H}$. Aoyagi et al. [3] have monitored the behavior of a FeTi sample, and as a result from the performed mechanical treatment, it was seen a formation of new activated surfaces and an improvement in the absorption/desorption reaction rate. Another example of fabrication method is the SICS (self-ignition combustion synthesis). It was proposed by NaotoYasuda et al. [4] for the following interests: purifying the product, hydriding an alloy directly and reduction of the hydrogenation time. It was seen also from literature that powder morphology or grain size is one of the major parameters that can be monitored in order to increase kinetics.

\section{2-Hydriding modeling and experimental comparison}

The present section is devoted to the thermodynamic model description. The model aims to describe the (de)hydriding reactions occurring inside a reactor containing a defined amount of hydride powders, fully activated and ready to start an absorption/desorption cycle. The hydride tank has a cylindrical shape which is coupled with a heat exchange (water flow on the outside surface). Based on the principles of energy balance, mass balance and ideal gas law equation, equations for both the absorption and desorption stage are proposed by B.A.Talaganis et al.[5]. These equations are listed in Table 1. The simulation is carried out assuming a set of assumptions: constant applied pressure during absorption and desorption, constant cooling or heating fluid temperature, uniform distribution of temperature inside the tank. The finite difference method is employed, i.e. all equations are discretized in time only, alloying to determine according to time: tank temperature, reaction rate, and hydride mass formed during reaction. 


\begin{tabular}{|c|c|c|}
\hline & Absorption & Desorption \\
\hline Energy balance & $\begin{array}{l}\left(m_{H_{2}} C p_{H_{2}}+m_{s} C p_{s}\right) \frac{d T}{d t}=\left(f_{i n} C p_{H_{2}}\right. \\
T)+A U\left(T_{i n}-\right. \\
T)-T)-\Delta H_{a} r m_{s} \frac{s c}{M W_{M H}}\end{array}$ & $\begin{array}{c}\left.C p_{H_{2}}+m_{s} C p_{s}\right) \frac{d T}{d t}=\left(f_{\text {out }} C p_{H_{2}}\left(T-T_{a t}\right)+\right. \\
A U\left(T_{w d}-T\right)+\Delta H_{d} r m_{s} \frac{s c}{M W_{M H}}\end{array}$ \\
\hline Rate reaction & $r=C_{a} e^{\frac{-E a}{R T}} \ln \left(\frac{P_{a}}{P_{e q}}\right)\left(1-\frac{m_{M H}}{m_{s}}\right)$ & $r=C_{d} e^{\frac{-E a}{R T}}\left(\frac{P d-p e q}{p e q}\right)\left(\frac{m_{M H}}{m_{s}}\right)$ \\
\hline Ideal gas law & $P_{a}=\frac{m_{H 2} R T}{M W_{H} \cdot V}$ & $P_{d}=\frac{m_{H 2} R T}{M W H . V}$ \\
\hline $\begin{array}{l}\text { Equilibrium } \\
\text { pressure }\end{array}$ & $p_{e q}=e^{\left(\frac{\Delta H a}{R T} \Delta \frac{\Delta S a}{R}\right)} P_{0}$ & $\boldsymbol{p}_{e q}=\boldsymbol{e}^{\left(-\frac{\Delta H d}{R T}+\frac{\Delta S d}{R}\right)} \boldsymbol{P}_{0}$ \\
\hline Hydride mass & $\frac{d m_{M H}}{d t}=r m_{s}$ & $\frac{d m_{M H}}{d t}=r m_{s}$ \\
\hline
\end{tabular}

Table 1-Absorption/desorption equations

In Table 2, all input parameters are listed with their values.

\begin{tabular}{|c|c|c|c|}
\hline Variables & Definition & FeTi-X & $\mathrm{LaNi}_{5}$ \\
\hline$C p_{H_{2}}$ & Heat capacity of $\mathrm{H}_{2}$ & 14.3 & 14.3 \\
\hline $\boldsymbol{m}_{s}$ & Solid mass & $100 g$ & $100 g$ \\
\hline$C p_{s}$ & Heat capacity of solid & $0.468 \mathrm{~J} / g . \mathrm{K}$ & $0.355 \mathrm{~J} / g . \mathrm{K}$ \\
\hline $\boldsymbol{U}$ & Over all heat transfer coefficient & $240 \mathrm{~W} / \mathrm{mK}$ & $240 \mathrm{~W} / \mathrm{mK}$ \\
\hline$T_{\text {in }}$ & $\mathrm{H}_{2}$ inlet temperature & $296 K$ & $296 K$ \\
\hline$T_{w a}$ & Cooling water temperature & $296 K$ & $296 K$ \\
\hline$\Delta \boldsymbol{H}_{\boldsymbol{a}}$ & Formation enthalpy of absorption & $-27.5 \mathrm{~kJ} / \mathrm{mol}$ & $-30.478 \mathrm{~kJ} / \mathrm{mol}$ \\
\hline$C_{a}^{a}$ & Pre-exponential factor & $16.41 / \mathrm{s}$ & $59.21 / \mathrm{s}$ \\
\hline$E_{a}^{a}$ & Activation energy of absorption & $23.8 \mathrm{~kJ} / \mathrm{mol}$ & $21.17 \mathrm{~kJ} / \mathrm{mol}$ \\
\hline$P_{a}^{a}$ & Absorption pressure & 10 bar & $10 \mathrm{bar}$ \\
\hline$\Delta \boldsymbol{S}_{a}$ & Formation entropy of absorption & -104.32 J/mol.K & $-108 \mathrm{~J} / \mathrm{mol} . \mathrm{K}$ \\
\hline$T_{a t}$ & Atmospheric pressure & $298 K$ & $298 K$ \\
\hline$T_{w d}$ & Heating water temperature & $296 K$ & $296 K$ \\
\hline$\Delta \boldsymbol{H}_{\boldsymbol{d}}$ & Formation enthalpy of desorption & $27.6 \mathrm{~kJ} / \mathrm{mol}$ & $30.8 \mathrm{KJ} / \mathrm{mol}$ \\
\hline$s c$ & Stoichiometric coefficient & 1 & 2.76 \\
\hline$C_{d}$ & Pre-exponential factor & $2.61 / \mathrm{s}$ & $9.61 / \mathrm{s}$ \\
\hline$E_{d}$ & Activation energy of desorption & $19.87 \mathrm{~kJ} / \mathrm{mol}$ & $16.42 \mathrm{~kJ} / \mathrm{mol}$ \\
\hline$\Delta \boldsymbol{S}_{d}$ & Formation entropy of desorption & $103.04 \mathrm{~kJ} / \mathrm{mol}$ & $108 \mathrm{~J} / \mathrm{mol} . \mathrm{K}$ \\
\hline$M W_{M H}$ & Molar mass of formed hydride & $103.7 \mathrm{~g} / \mathrm{mol}$ & $432 \mathrm{~g} / \mathrm{mol}$ \\
\hline$P d$ & Applied desorption pressure & $0.068 \mathrm{bar}$ & 0.068 bar \\
\hline
\end{tabular}

Table 2- Input variables and their values

In this study, attention is paid on the behavior of the FeTi-X when $100 \mathrm{~g}$ of this intermetallic powder is filled into the cylindrical tank and subjected to 10 bar of constant hydrogen pressure. The external heat exchange is natural convection. Figure 1 shows hydride reaction rate and temperature response during absorption. 
Same profile is observed for both temperature and absorption rate evolution. Simulations predict an extremely fast response of the system. Maximum temperature and absorption are reached before 100s, then both quantities decrease rapidly and reaction ends after 10 minutes. The pick of absorption rate occurs a bit earlier, after less than 1 minute.

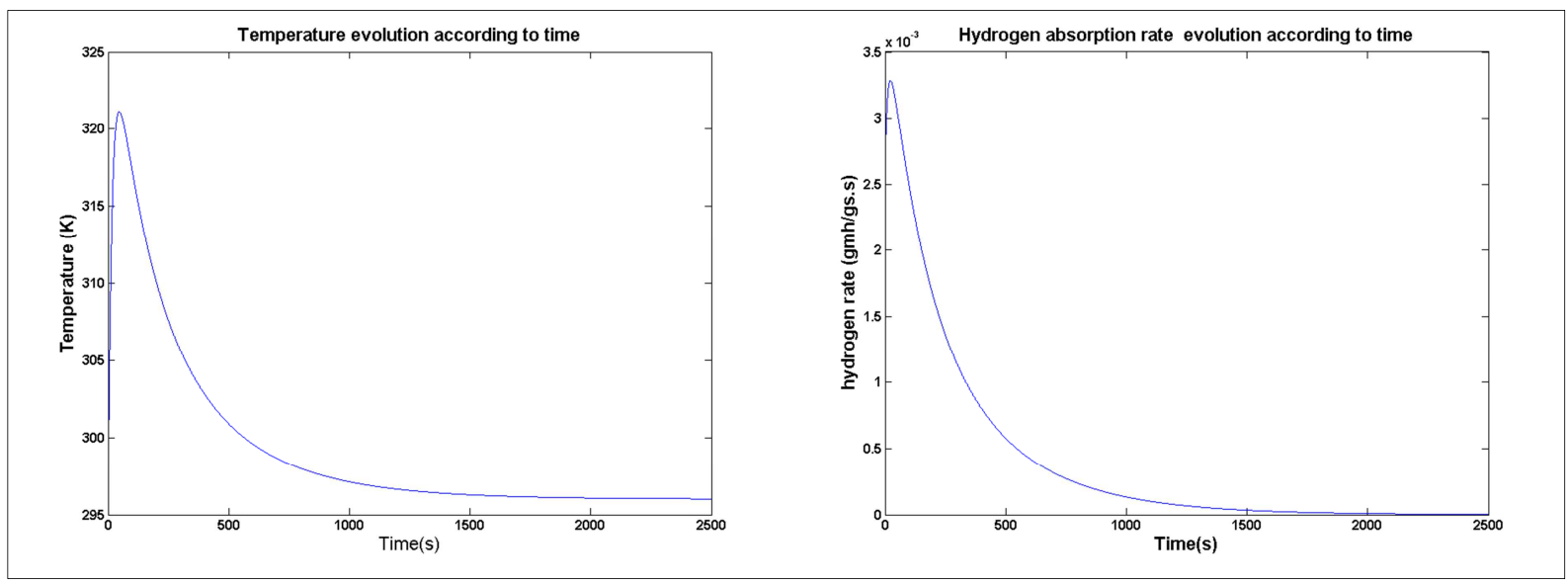

Figure 1-Simulation results (reaction rate and temperature evolution according to time of FeTi-X)

Having a simulating tool to predict numerically the FeTi-X alloy response during hydriding, turns out to be really advantageous, in order to understand the various steps of the reaction. However, in order to make it efficient, it is required to have a comparison with experimental results. To do so, a $100 \mathrm{~g}$ of FeTi-X is filled into a hydrogen reactor coupled with a thermocouple, and putted under the following thermal conditions: cooling and heating is done under room temperature (natural convection with a coefficient of convection of $10 \mathrm{~W} / \mathrm{mK}$ ). Fig-2 present schematically all the components of the bench test that has been used to perform this investigation.

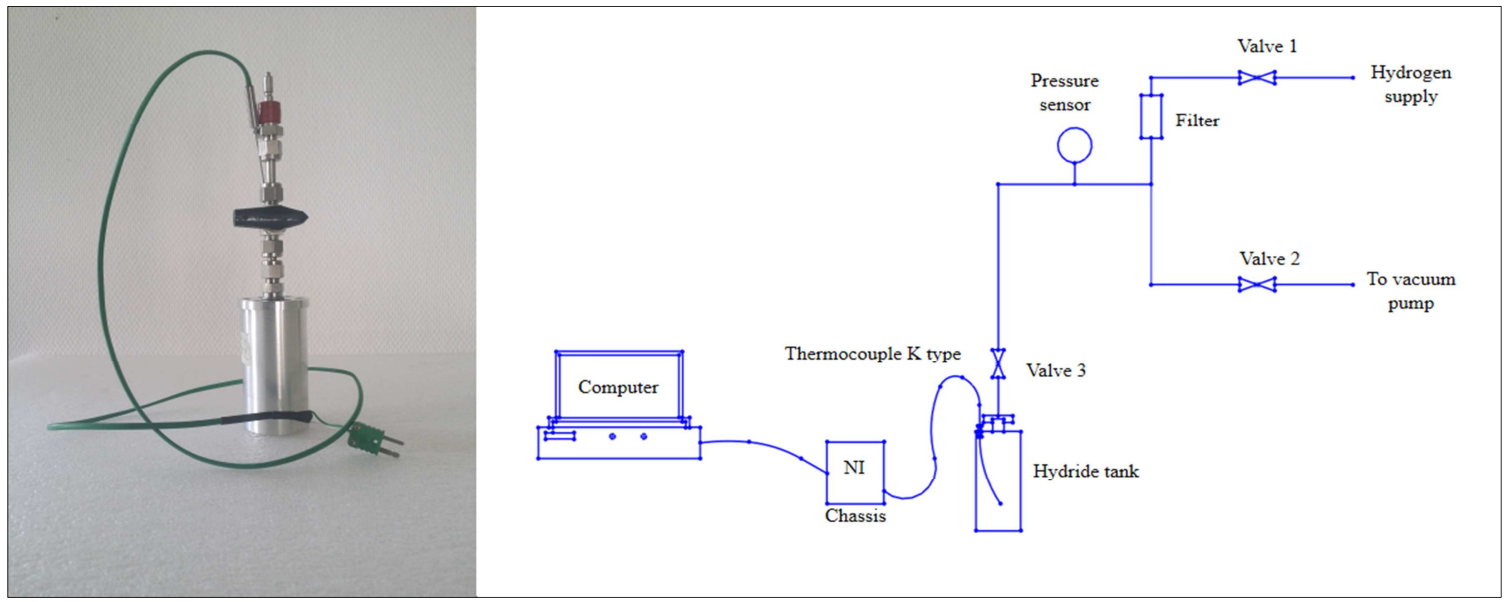

Figure. 2- Hydriding reactor and bench test

The FeTi-X sample is first subjected to a pressure of 20bar (constant according to time). It is observed a small increase in temperature after $3000 \mathrm{~min}$. Then the powder is subjected to vacuum, and again a pressure of 60bar is applied in order to force the activation mechanism. In this stage, a higher amplitude temperature pick is observed but still requires 1350 min to occur. The powder is subjected once again to vacuum, and finally a pressure of $10 \mathrm{bar}$ is applied twice, allowing to guaranty the complete activation of the sample and to ensure repeatability. 
Figure -3 shows the experimental curves of the activation process, and a comparison between experimental and simulation results.

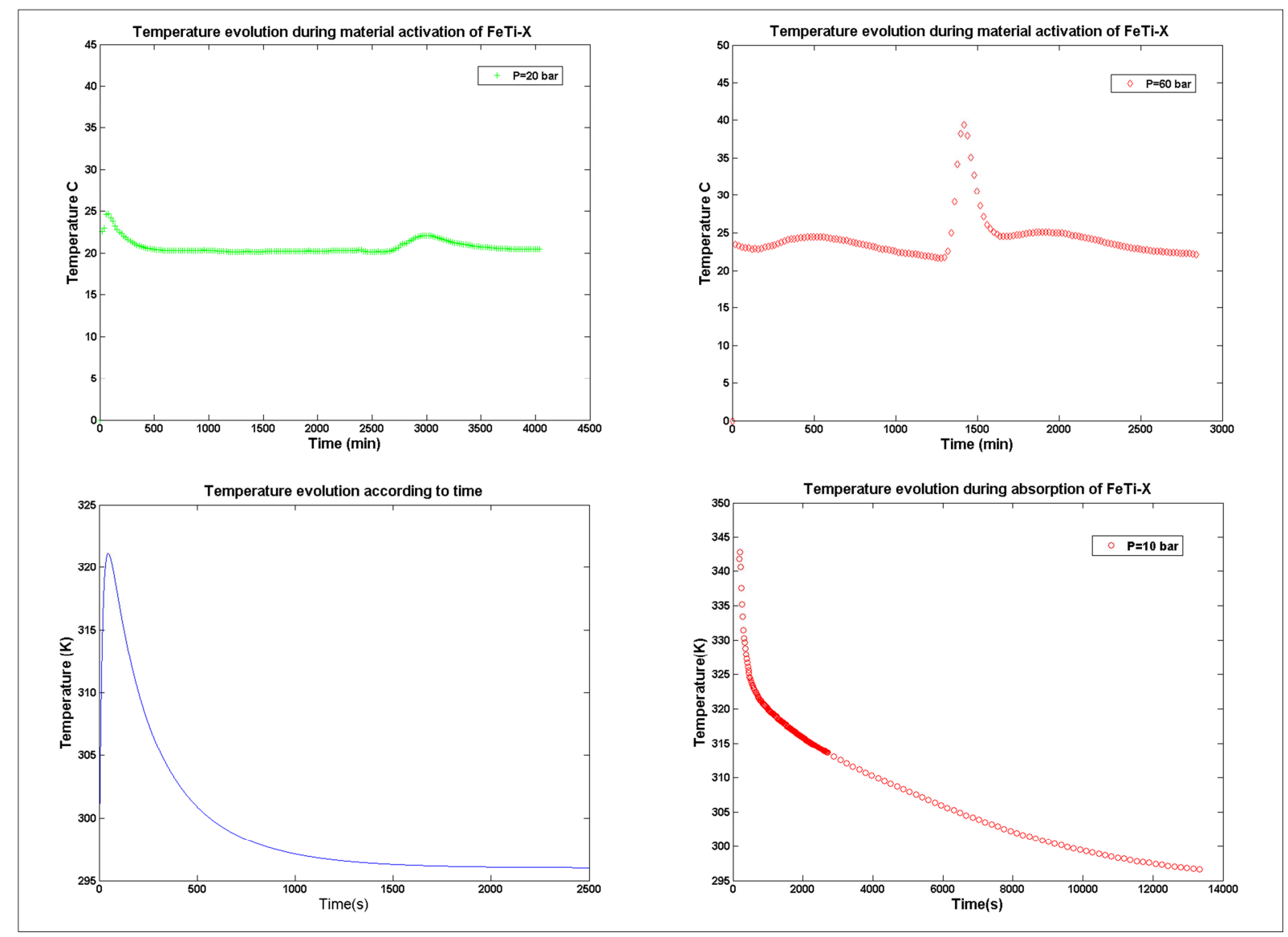

Figure 3 -Temperature evolution according to time during the activation mechanism of FeTi-X, and comparison between simulation and experiment for the first cycle

The two temperature curves beneath in Fig. 3 show a comparison between experimental result (on top right) and simulation result (on top left). Simulation result confirms the overall tendency, i.e. a fast increase of temperature with comparable maximum value, followed with a slow cooling till ambient temperature. Retrieving the accurate properties of FeTi-X in order to improve the good correlation between the model and the experimental results will require to describe more precisely physical phenomena and to lighten hypothesis.

\section{3-Sensiblity analysis of the thermodynamic model}

Regarding mathematical models, they are most of the time of complex form and involve a huge numbers of input parameters. It's so important to classify input parameters by order of their impact on the output data. The prioritization allows to define on what input parameters attention is to be paid. This classification is here obtained using a sensibility study based on screen design methods. Doing so, all input factors are ranked in order of influence, but from a qualitative point of view. In this paper, Morris design method is used to manage the sensibility analysis on the thermodynamic model. This method imposes variation of one input factor at a time. Sensitivity is related to two factor indicators, proposed by Morris method: $\mu$ that evaluates the overall effect of the input on the output and $\sigma$ that gives the coupling effect 
between input factors. In order to perform a global sensitivity approach, elementary effect of each input must be identified as follow:

$$
\begin{aligned}
& E_{i}=\left|\frac{f\left(x+\xi e_{i}\right)-f(x)}{\xi}\right| \\
& \mu=\operatorname{mean}\left(E_{i}\right) \\
& \sigma=\operatorname{Std}\left(E_{i}\right)
\end{aligned}
$$

Where $\xi e_{i}$ is a small perturbation induced to an input in the direction of the unit $e_{i}$ vector.

Calculation of the sensibility analysis is done using dedicated in-house Matlab® software, called SIMBAD. Here after, all input and output parameters used in this study are listed:

1-Input parameters: $\mathbf{T}_{\text {in }}, \mathbf{A}, \mathbf{T}_{\mathbf{w a}}, \Delta \mathbf{H}_{\mathbf{a}}, \Delta \mathbf{S}_{\mathbf{a}}, \mathbf{m}_{\mathbf{s}}, \mathbf{E a}, \mathbf{P a}, \mathbf{C}_{\mathbf{a}}, \mathbf{U}, \mathbf{C p}_{\mathbf{H}_{2}}$, and $\mathbf{V}$.

2- Output parameter: $\boldsymbol{r}_{\boldsymbol{a}}$ (absorption reaction rate)

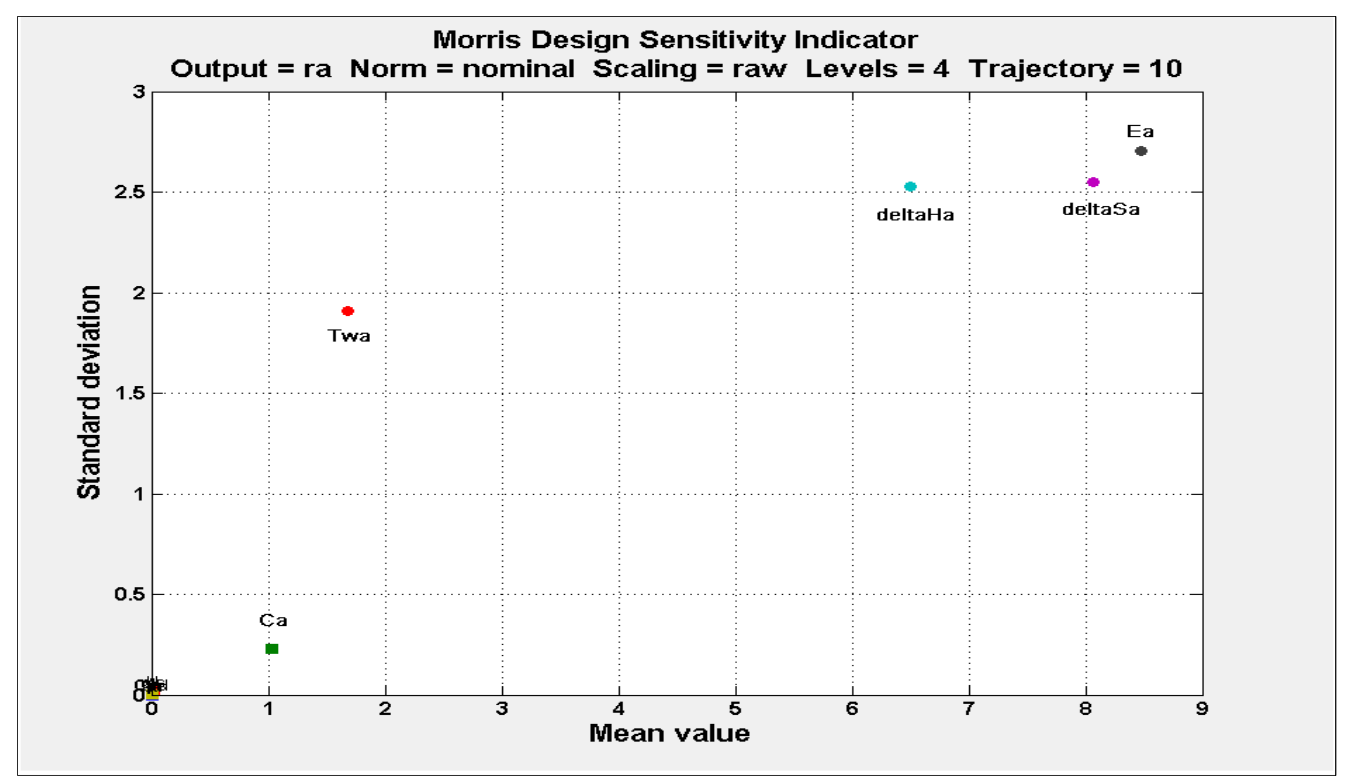

Figure 4-Morris design sensitivity indicator

In Fig. 4, all input variables are ranked according their elementary effect mean value and standard deviation. This analysis leads to the conclusion that activation energy Ea has the most important nonlinear effect, i.e. it is coupled with other input parameters. Then, $\Delta \mathbf{H}_{\mathbf{a}}, \Delta \mathbf{S}_{\mathbf{a}}$ come after and their effect is also nonlinear. As a general explanation, variables that have the greatest mean value are the most sensible parameters and depending on the standard deviation value, effect can be linear or nonlinear: the more $\operatorname{Std}\left(E_{i}\right)$ is great, the more non linearity effect increases. From Fig. 4, we can rank input parameters by order of importance as follow: Ea $>\Delta \mathbf{S}_{\mathbf{a}}>\Delta \mathbf{H}_{\mathbf{a}}>\mathbf{T}_{\mathbf{w a}}>\mathbf{C}_{\mathbf{a}}$ and other inputs have negligible effects. Consequently, improving the accuracy of predicted hydride tank responses requires determining with care values of these parameters but also their evolution with the temperature. 


\section{4-Conclusion}

The present paper aims to contribute at developing strategies in order to increase absorption/desorption of Fe-Ti based alloys. We present a macro scale thermodynamic model, that simulates the response of a FeTi-X hydride tank, and in parallel we introduce a bench test which is employed to establish a comparison between experimental and numerical results. It has been clearly seen that material properties have to be more precisely identified in so far to ensure more accurate fitting between experiments and simulation results. Finally, a sensibility analysis is performed to evidence the most influent input variables: i.e. variables that change widely output results, such as reaction rate. In order to get a robust model and excellent fitting between simulation and experiment, a model calibration must be performed and lighter hypothesis introduced.

\section{Acknowledgements}

Authors would like to thanks Scott Cogan, researcher at the Applied Mechanics Department of the FEMTO ST Institute, to offer them the opportunity to use the SIMBAD Matlab® software. It is dedicated to the sensitivity analysis but also to model optimization.

\section{References:}

[1] K. Kim, B. Montoya, A. Razani, K.-H.Lee. International journal of hydrogen energy 26 (2001) 609-613

[2] P.Mandal, O.N.Srivastava. Journal of Alloys and Compounds, 205 (1994) 111-118

[3] H. Aoyagi, K. Aoki, T. Masumoto. Journal of Alloys and compounds 231 (1995) 804-809

[4] N. Yasuda, R. Wakabayashi, S. Sasaki, N. Okinaka, T. Akiyama. International journal of hydrogen energy 34 (2009) 9122-9127

[5] B.A. Talaganis, G.O.Meyer, P.A Aguirre, International journal of hydrogen energy 36 (2011) 13621-13631

[6] H.I. Miller, J. Murray, E. Laury, J. Reinchart, A.J. Goudy. Journal of alloys and compounds 231 (1995) 670-674 